\title{
Abnormal hematological indices in cirrhosis
}

\author{
Amir A Qamar MD, Norman D Grace MD
}

\begin{abstract}
AA Qamar, ND Grace. Abnormal hematological indices in cirrhosis. Can J Gastroenterol 2009;23(6):441-445.

Abnormalities in hematological indices are frequently encountered in cirrhosis. Multiple causes contribute to the occurrence of hematological abnormalities. Recent studies suggest that the presence of hematological cytopenias is associated with a poor prognosis in cirrhosis. The present article reviews the pathogenesis, incidence, prevalence, clinical significance and treatment of abnormal hematological indices in cirrhosis.
\end{abstract}

Key Words: Anemia; Cirrhosis; Hypersplenism; Leukopenia; Thrombocytopenia

\section{Indices hématologiques anormaux dans la cirrhose}

On observe souvent des anomalies des indices hématologiques dans la cirrhose. Plusieurs causes contribuent à ces anomalies hématologiques. De récentes études donnent à penser que la présence de cytopénies hématologiques soit associée à un pronostic sombre dans la cirrhose. Le présent article passe en revue la pathogenèse, l'incidence, la prévalence, la portée clinique et le traitement des indices hématologiques anormaux dans la cirrhose.
$\Delta$ bnormalities in hematological parameters are common in Apatients with cirrhosis. The pathogenesis of abnormal hematological indices (HIs) in cirrhosis is multifactorial and includes portal hypertension-induced sequestration, alterations in bone marrow stimulating factors, viral- and toxin-induced bone marrow suppression and consumption or loss (Tables 1-4). Abnormalities in HIs are associated with an increased risk of complications including bleeding and infection. The present article reviews the pathogenesis, occurrence, incidence and clinical significance of abnormal HIs in cirrhosis.

\section{PATHOGENESIS}

\section{Portal hypertension}

Splenic sequestration and destruction of platelets, white blood cells (WBCs) and red blood cells (RBCs) in the portal hypertension-induced enlarged spleen is defined as hypersplenism (1). In patients with cirrhosis, there is a redistribution of platelets, with up to $90 \%$ of the circulating platelet mass located in the enlarged spleen (2-4). Similarly, splenic sequestration of RBCs contributes to the anemia of liver disease. Using ${ }^{51} \mathrm{Cr}$-labelled RBCs, Subiyah and Al-Hindawi (5) demonstrated a correlation between a decrease in RBC survival and splenomegaly related to portal hypertension. They also showed that splenectomy resulted in improved RBC survival. Blackman et al (6) investigated the disappearance rates of autologous granulocytes in the blood of 20 patients with alcoholic cirrhosis. Granulocytes were labelled with ${ }^{32}$ P-labelled diisopropyl fluorophosphate ( $\left.{ }^{32} \mathrm{DFP}\right)$, and disappearance curves were obtained and correlated with splenic pulp pressure and size. Portal pressures were estimated by splenic pulp pressure. A biphasic curve was obtained in which $59 \%$ of ${ }^{32}$ DFP-labelled granulocytes were recovered in an initial rapid phase. This initial phase correlated with splenic pulp pressure but not splenic size. In the second phase, the remaining granulocytes disappeared at a slower rate. Overall, there was no relationship between granulocyte recovery and spleen size or splenic pulp pressure, suggesting that sequestration occurs outside of the spleen, possibly in the splanchnic circulation.
In patients with compensated cirrhosis, we have shown $(7,8)$ a significant correlation between the hepatic venous pressure gradient (HVPG [a marker of portal hypertension]), and HI. However, there was only a mild to moderate correlation between platelet counts, WBC counts and hemoglobin. This suggests that other factors, in addition to splenic sequestration, contribute to the occurrence of abnormal HIs in cirrhosis. For both leukopenia and anemia, portal hypertension appears to have a limited contribution.

\section{HEMATOPOIETIC GROWTH HORMONES Thrombopoietin}

Thrombopoietin is produced by liver, kidney, muscle and bone marrow, and its synthesis is mainly dependent on hepatic function. Thrombopoietin stimulates the production and differentiation of megakaryocytes into mature platelets. Studies have shown it to be effective in increasing the platelet count in noncirrhotic conditions. Numerous studies have evaluated thrombopoietin in cirrhosis. Peck-Radosavljevic et al (9) evaluated peripheral thrombopoietin levels in 28 patients with cirrhosis, none of whom had detectable thrombopoietin. However, seven of these patients underwent liver transplantation, with an increase in the thrombopoietin level two days after surgery. On the other hand, five of these patients, who underwent decompression for portal hypertension, showed no improvement in thrombopoietin levels. In a similar study, Martin et al (10) were unable to detect plasma thrombopoietin in 39 of 44 patients with cirrhosis. They also noted that among 16 of 17 patients who underwent liver transplantation, thrombopoietin became detectable. Subsequent studies have confirmed these findings (11-15).

Because the liver is one of the major organs that produces thrombopoietin, alterations in hepatic perfusion may alter either the synthesis or release of the hormone. Giannini et al (16) used a monoethylglycinexylidide test, which is partially dependant on hepatic perfusion, to assess thrombopoietin levels. They demonstrated a modest correlation between monoethylglycinexylidide test times and thrombopoietin levels in 
TABLE 1

\section{Causes of thrombocytopenia in cirrhosis}

Portal hypertension-induced splenic sequestration

Alterations in thrombopoietin

Bone marrow suppression mediated by toxins (eg, alcohol, hepatitis B and C)

Consumptive coaguloapathy (eg, low-grade disseminated intravascular

coagulation, acquired intravascular coagulation and fibrinolysis)

Increased blood loss (eg, hemorrhage)

\section{TABLE 2}

\section{Causes of leukopenia in cirrhosis}

Portal hypertension-induced splenic and splanchnic sequestration

Alterations in granulocyte-colony stimulating factor and granulocyte macrophage-colony stimulating factor

Bone marrow suppression mediated by toxins (eg, alcohol, hepatitis B and C)

patients with cirrhosis. This suggests that hepatic perfusion may play a role in regulating thrombopoietin levels. Rios et al (17) found that thrombopoietin levels correlated with spleen size but not platelet count. After these patients underwent partial splenic embolization, the physiological relationship between thrombopoietin levels and platelet counts was restored. The report concluded that increased thrombopoietin degradation in the portal hypertension-congested spleen may contribute to the thrombocytopenia of cirrhosis.

In 19 patients with cirrhosis, Sezai et al (18) showed that hepatofugal circulation, which is generally associated with lower portal venous pressures and less severe portal hypertension, had a lower hepatic vein to portal vein ratio of thrombopoietin. This suggests that a certain perfusion pressure may be needed for the release of thrombopoietin. However, a larger study is needed to confirm these findings. Furthermore, the authors used the portovenous pressure to assess portal hypertension, which does not account for intrahepatic sinusoidal hypertension. A more accurate determinant of portal hypertension is HVPG; this measurement should be used in future studies.

\section{Anemia}

Erythropoietin is produced predominantly by the kidney but also by the liver. It protects RBCs from apoptosis and enhances the development of precursor RBCs. Yang et al (19) investigated the significance of erythropoietin in 67 patients with varying severity of cirrhosis, and reported that plasma erythropoietin levels were significantly higher in cirrhotic patients than in controls. They also found levels to be higher in patients with anemia. Interestingly, they demonstrated a positive correlation between the HVPG and erythropoietin, and a negative correlation between hepatic blood flow and erythropoietin. Bruno et al (20) found an increase in erythropoietin in cirrhotic patients with anemia only when the hemoglobin level was less than $120 \mathrm{~g} / \mathrm{L}$. The authors believed that the erythropoietin response was blunted in comparison with other causes of anemia such as iron deficiency.

\section{WBC stimulating factors}

Very little is known about the role of granulocyte colonystimulating factor (G-CSF) or granulocyte macrophage colonystimulating factor (GM-CSF) in leukopenia associated with cirrhosis. These factors are produced by the immune cells to
TABLE 3

Causes of abnormal hematological indices in cirrhosis

Portal hypertension-induced splenic sequestration

Alterations in erythropoietin

Bone marrow suppression mediated by toxins (eg, alcohol, hepatitis B and C) Increased blood loss (eg, hemorrhage, hemolysis)

\section{TABLE 4}

Association between hematopoietic stimulating factors and thrombocytopenia, anemia and leukopenia in cirrhosis

\begin{tabular}{ll}
\hline Hematopoietic stimulating factor & Association with cirrhosis \\
Thrombopoietin & $\begin{array}{c}\text { Significant association with the } \\
\text { presence of thrombocytopenia }\end{array}$ \\
Erythropoietin & Possible association, data limited \\
Granulocyte colony-stimulating factor & No data \\
\hline
\end{tabular}

stimulate the bone marrow to produce and release granulocytes and stem cells into the circulation. They also have a role in the differentiation and function of mature neutrophils. Gurakar et al (21) have shown that GM-CSF treatment for seven days in patients with cirrhosis and leukopenia resulted in an increase in the WBC count. Moreover, they showed no increase in the fraction of trapped leukocytes in the spleen.

\section{Bone marrow suppression}

Viral hepatitis B or C, excess alcohol consumption and medications are commonly associated with cirrhosis and an increased risk of pancytopenia due to bone marrow suppression as a result of bone marrow hypoplasia. Interferon, azathioprine and mycophenolate mofetil are examples of medications that may cause pancytopenia in patients with cirrhosis.

\section{Other factors}

Many other factors contribute to the development of abnormal HIs in cirrhosis. Patients with portal hypertension may experience occult or chronic bleeding from portal hypertensive gastropathy and/or enteropathy, leading to anemia and thrombocytopenia. Patients with ongoing alcohol consumption may have hemolysis, which exacerbates anemia. Low-grade disseminated intravascular coagulation may contribute to thrombocytopenia in patients with decompensated cirrhosis.

\section{Prevalence \\ ABNORMAL HIs IN CIRRHOSIS}

Heterogenous studies of patients with varying stages of cirrhosis have shown a prevalence of abnomal HIs ranging from $6 \%$ to $77 \%$ (22-29). Many of these studies, however, consist of patients with differing severities of cirrhosis with or without decompensation. In a recent analysis of homogenous patients with compensated Child-Pugh class A/B cirrhosis, $84 \%$ were found to have abnormalities in the $\mathrm{HI}$, defined as a platelet count of less than or equal to $150 \times 10^{9} / \mathrm{L}, \mathrm{WBC}$ count of less than or equal to $400 \times 10^{9} / \mathrm{L}$ or hemoglobin level less than or equal to $135 \mathrm{~g} / \mathrm{L}$ for men and $115 \mathrm{~g} / \mathrm{L}$ for women. Thirty-two per cent of these patients had a combination of cytopenias (8). Thrombocytopenia was the most common single abnormality, and thrombocytopenia and leukopenia was the most common combined abnormality. 




Figure 1) The prevalence of abnormal hematological indices in cirrhosis patients with clinically significant (hepatic venous pressure gradient $\geq 10 \mathrm{mmHg}$ ) compared with clinically insignificant (hepatic venous prssure gradient $<10 \mathrm{mmHg}$ ) portal hypertension $(n=213)$. Anemia defined as a hemoglobin level of less than $135 \mathrm{~g} / \mathrm{L}$ for men and less than $115 \mathrm{~g} / \mathrm{L}$ for women. Leukopenia defined as a white blood cell count of less than $400 \times 10^{9} / \mathrm{L}$. Thrombocytopenia defined as a platelet count of less than $150 \times 10^{9} / \mathrm{L}$

\section{Incidence}

Assessment of the true occurrence of abnormal HIs in cirrhosis is limited by the cross-sectional design of most studies reporting these findings. Recently, a cohort of 34 patients with compensated Child-Pugh class A/B cirrhosis with a normal baseline HI were followed longitudinally for approximately five years to determine the sequence of abnormal HIs in cirrhosis (8). Thrombocytopenia was the most common and earliest $\mathrm{HI}$ abnormality to develop, followed sequentially by anemia and thrombocytopenia.

\section{Clinical significance}

The occurrence of thrombocytopenia, leukopenia or anemia in patients with cirrhosis may have significant clinical implications. They may be a limiting factor when considering invasive procedures such as liver biopsy, paracentesis, or dental, endoscopic or surgical procedures. Leukopenia may also increase the risk for infection. Chronic anemia may contribute to a poorer outcome after any hemorrhagic episode.

There is now evidence to support the increased morbidity and mortality associated with hypersplenism. Liangpunsakul et al (30) reported that the presence of severe hypersplenism independently predicted the development of variceal bleeding and death.

A study (8) evaluating the risk of death or transplant among 213 patients with compensated Child-Pugh class A/B cirrhosis reported that both thrombocytopenia and leukopenia were significantly associated with an increased risk of morbidity and mortality, even when controlling for factors such as ChildPugh score, portal hypertension as determined by the HVPG or alcohol use. The greatest risk occurred in patients who had both thrombocytopenia and leukopenia. The prevalence of abnormal HIs differed in patients with clinically significant portal hypertension (HVPG $10 \mathrm{mmHg}$ or higher) compared with clinically insignificant portal hypertension (HVPG less than $10 \mathrm{mmHg}$ ) (Figure 1).

Thrombocytopenia has been suggested to be a noninvasive marker for the presence of esophageal varices. Many studies (31-35) have reported a wide range of platelet count thresholds that would prompt examinations using upper endoscopy

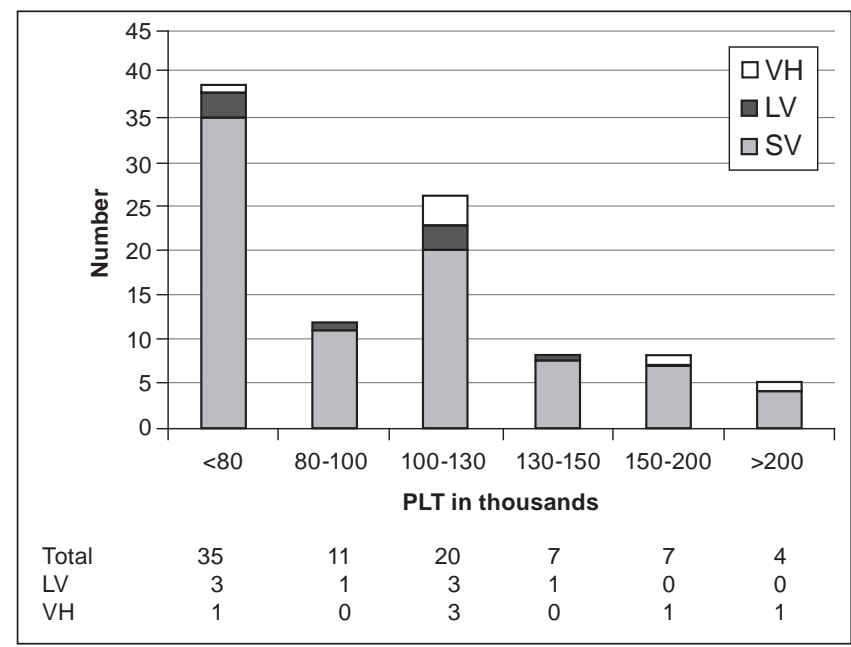

Figure 2) Relationship between the presence of small varices (SV), large varices $(\mathrm{LV})$, variceal hemorrhage $(\mathrm{VH})$ and platelet count (PLT) ranges at the time of occurrence of varices or VH. Adapted from reference 7

to screen for esophageal varices. The interpretation of these studies was limited by their cross-sectional nature and the differing severity of cirrhosis among included subjects. Our group recently addressed this issue by analyzing patients included in a prospective, randomized controlled study (7) in which subjects were followed for a median of 54.9 months. Crosssectional evaluation found no platelet count threshold that was clinically useful for indicating the presence of gastroesophageal varices. Surprisingly, $14 \%$ of patients with large varices or variceal hemorrhage had normal platelet counts (Figure 2). Longitudinal evaluation of platelet counts fared no better and was found to be inadequate for predicting the occurrence of gastroesophageal varices in compensated cirrhosis. Thus, it can be concluded that the use of platelet counts is inadequate for detecting the presence or occurrence of gastroesophageal varices in cirrhosis.

\section{TREATMENT}

Treatment of abnormal HIs in cirrhosis involves a multifaceted approach. Prevention of bleeding with gastrointestinal prophylaxis using proton pump inhibitors, and transfusion of platelets before procedures may reduce the risk of exacerbating underlying $\mathrm{HI}$ abnormalities. Advising patients to reduce alcohol intake can prevent further exacerbation of HI abnormalities. However, presently, reduction of portal pressure and the use of hematopoietic growth factors are the most often used treatments.

\section{Reduction of portal hypertension}

Portosystemic shunts: Many studies have shown an improvement in the HI when portal pressures are reduced using surgical or transjugular intrahepatic portosystemic shunts (TIPS). Felix et al (36) compared leukopenia and thrombocytopenia among patients treated with either a portocaval shunt or conventional medical therapy. Patients in the medical group did not receive beta-blockers or nitrates. Leukopenia improved in 50\% of the subjects in the surgical group compared with only $14 \%$ in the medical group. Similarly, thrombocytopenia improved in $43 \%$ 
of subjects in the surgical group compared with $0 \%$ in the medical group. The greatest benefit occurred when the preshunt portal pressure was greater than $30 \mathrm{mmHg}$ and reduced by at least $10 \mathrm{mmHg}$ after surgery. A postshunt portal pressure above $15 \mathrm{mmHg}$ was most likely to be associated with an improvement in both thrombocytopenia and leukopenia. In the study, 100\% of subjects with postshunt portal pressures greater than $15 \mathrm{mmHg}$ had an improved $\mathrm{HI}$, compared with only $50 \%$ in the group with postshunt portal pressures of less than $15 \mathrm{mmHg}$. They also found that when the postshunt portal pressures were reduced by more than $10 \mathrm{mmHg}$, the $\mathrm{HI}$ improved in $100 \%$ of subjects compared with only $44 \%$ among those with less than a $10 \mathrm{mmHg}$ reduction. These findings have been confirmed (26,37-41). In contrast, Mutchnick et al (42) and other groups $(43,44)$ have demonstrated the disappearance of thrombocytopenia with equal frequency among patients who underwent surgical portosystemic shunting compared with controls.

Similar to the results demonstrated with surgical shunts, many studies have shown that TIPS improved HIs (45-48). Gschwantler et al (45) showed an average increase of 19\% in platelet count after the placement of TIPS compared with a $17 \%$ decrease in controls. Similar to the findings of Felix et al (36) with surgically created shunts, subjects with higher postTIPS portal pressures had a greater improvement in thrombocytopenia. A post-TIPS gradient of $12 \mathrm{mmHg}$ or higher had a twofold greater increase in thrombocytopenia compared with individuals who had a gradient of less than $12 \mathrm{mmHg}$. However, a number of groups have shown no difference in platelet and WBC counts after TIPS placement (49-51). Sanyal et al (49) reported a subgroup of patients that had TIPS placed for ascites in whom the platelet count increased by more than $25 \%$. The mean post-TIPS gradient in this group was $12 \mathrm{mmHg}$.

Nonselective beta-blockers: If abnormalities in the $\mathrm{HI}$ are at least partially related to portal hypertension, then a reduction in portal pressure related to treatment with nonselective betablockers might be expected to show an improvement in the abnormal HI. Preneta et al (52) reported that patients with cirrhosis and esophageal varices treated with propranolol had a $37 \%$ increase in platelet count compared with a $3.8 \%$ decrease in controls. This was associated with a greater reduction in HVPG after propranolol therapy (propranolol $10.7 \%$ versus placebo $6.7 \%$ ). However, patients achieving a significant reduction in HVPG (ie, more than 20\%) had a paradoxical reduction rather than the expected increase in platelet count. Sekai et al (53) treated 19 patients with propranolol or placebo for one week. Using Doppler ultrasonography to measure splenic artery hemodynamics, they found that propranolol improved splenic artery pulsatility and increased platelet count by $16 \times 10^{9} / \mathrm{L}$, compared with no effect using placebo.

These data suggest that the effect of beta-blockers in producing an improvement in platelet count is variable and may be related to factors other than decompression of portal hypertension.

\section{HEMATOPOIETIC GROWTH FACTORS \\ Thrombopoietin}

An important study using the thrombopoietin receptor agonist eltrombopag was recently published (54). In 74 patients with cirrhosis who had platelet counts between $20 \times 10^{9} / \mathrm{L}$ and $70 \times 10^{9} / \mathrm{L}$, treatment with eltrombopag or placebo was administered for four weeks. Platelet count increased to greater than $100 \times 10^{9} / \mathrm{L}$ in $75 \%$ to $95 \%$ of the patients treated with eltrombopag compared with no increase in patients treated with placebo. Certain concerns, however, remain. First, the effect of eltrombopag on the coagulable state or malignancy risk is unknown. Second, because portal hypertension appears to influence thrombopoietin, it may also influence eltrombopag's effect on platelet counts. Finally, the hemostatic effect of the increased platelet count as a result of eltrombopag treatment in cirrhosis is unknown.

\section{Erythropoietin}

Patients with hepatitis $\mathrm{C}$ virus cirrhosis who receive antiviral therapy with interferon and ribavirin are at higher risk of developing anemia. These patients have been treated successfully with erythropoietin agents, with noted improvement in hemoglobin levels $(55,56)$. Whether treatment benefits patients with cirrhosis in settings other than antiviral therapy is not known. Studies investigating the effect of preventing anemia in cirrhosis are lacking.

\section{G-CSF and GM-CSF}

GM-CSF has been safely used in patients with cirrhosis and leukopenia, with an improvement in WBC counts. However, it is unknown whether this increase in WBC count is associated with a reduced risk of infection (21).

\section{SUMMARY}

There has been great progress in our understanding of the occurrence, clinical significance and treatment of abnormal HIs in cirrhosis. A number of different factors contribute to abnormal HIs in cirrhosis, but portal hypertension and alterations in bone marrow hormones appear to be the strongest contributors. The occurrence of abnormal HIs is associated with a poor clinical outcome. This may be related to clinical consequences of hematological abnormalities including the risk of bleeding and infection. Reduction of portal pressure using pharmacological agents and shunt procedures have a variable effect on the improvement of abnormal HIs. The potential benefit of recombinant growth factors and analogues needs to be assessed in well-designed, prospective clinical trials.

\section{REFERENCES}

1. Peck-Radosavljevic M. Hypersplenism. Eur J Gastroenterol Hepatol 2001;13:317-23.

2. Peck-Radosavljevic M. Thrombocytopenia in liver disease. Can J Gastroenterol 2000:13(Suppl D):60D-6D.

3. Toghill PJ, Green S, Ferguson F. Platelet dynamics in chronic liver disease with special reference to the role of the spleen. J Clin Pathol 1977;30:367-71.

4. Aster RH. Pooling of platelets in the spleen: Role in the pathogenesis of hypersplenic thrombocytopenia. J Clin Invest 1966;45:645-57.

5. Subiyah BW, Al-Hindawi A. Red cell survival and splenic accumulation of radiochromuim in liver cirrhosis with splenomegaly. Br J Haematol 1967;13:773-8.

6. Blackman A, Grace N, Chandler H, et al. Hypersplenism in cirrhosis: Measurements of portal pressure, spleen size and circulating blood cell disappearance rates. Clin Res 1969;17:A298.

7. Qamar AA, Grace ND, Groszmann RJ, et al. Platelet count is not a predictor of the presence or development of gastroesophageal varices in cirrhosis. Hepatology 2008;47:153-9. 
8. Qamar AA, Grace ND, Groszmann RJ, et al. The incidence, prevalence and clinical significance of abnormal hematological indices in patients with compensated cirrhosis. Clin Gastroenterol Hepatol 2009, In press.

9. Peck-Radosavljevic M, Zacherl J, Meng YG, et al. Is inadequate thrombopoietin production a major cause of thrombocytopenia in cirrhosis of the liver? J Hepatol 1997;27:127-31.

10. Martin TG III, Somberg KA, Meng YG, et al. Thrombopoietin levels in patients with cirrhosis before and after orthotopic liver transplantation. Ann Intern Med 1997;127:285-8.

11. Goulis J, Chau TN, Jordan S, et al. Thrombopoietin concentrations are low in patients with cirrhosis and thrombocytopenia and are restored after orthotopic liver transplantation. Gut 1999;44:754-8.

12. Stiegler G, Stohlawetz P, Peck-Radosavljevic M, et al. Direct evidence for an increase in thrombopoiesis after liver transplantation. Eur J Clin Invest 1998;28:755-9.

13. Kawasaki T, Takeshita A, Souda K, et al. Serum thrombopoietin levels in patients with chronic hepatitis and liver cirrhosis. Am J Gastroenterol 1999;94:1918-22.

14. Peck-Radosavljevic M, Wichlas M, Zacherl J, et al. Thrombopoietin induces rapid resolution of thrombocytopenia after orthotopic liver transplantation through increased platelet production. Blood 2000;95:795-801.

15. Peck-Radosavljevic M, Zacherl J, Wichlas M, et al. Thrombopoietic cytokines and reversal of thrombocytopenia after liver transplantation. Eur J Gastroenterol Hepatol 1999;11:151-6.

16. Giannini E, Botta F, Borro P, et al. Relationship between thrombopoietin serum levels and liver function in patients with chronic liver disease related to hepatitis $\mathrm{C}$ virus infection. Am J Gastroenterol 2003;98:2516-20.

17. Rios R, Sangro B, Herrero I, et al. The role of thrombopoietin in the thrombocytopenia of patients with liver cirrhosis. Am J Gastroenterol 2005;100:1311-6.

18. Sezai S, Kamisaka K, Ikegami F, et al. Regulation of hepatic thrombopoietin production by portal hemodynamics in liver cirrhosis. Am J Gastroenterol 1998;93:80-2.

19. Yang YY, Lin HC, Lee WC, et al. Plasma erythropoietin level in patients with cirrhosis and its relationship to the severity of cirrhosis and renal function. J Gastroenterol Hepatol 2003;18:1156-61.

20. Bruno CM, Neri S, Sciacca C, et al. Plasma erythropoietin levels in anaemic and non-anaemic patients with chronic liver diseases. World J Gastroenterol 2004;10:1353-6.

21. Gurakar A, Fagiuoli S, Gavaler JS, et al. The use of granulocytemacrophage colony-stimulating factor to enhance hematologic parameters of patients with cirrhosis and hypersplenism. J Hepatol 1994;21:582-6.

22. Morlock CG, Hall BE. Association of cirrhosis, thrombocytopenia and hemorrhagic tendency. Arch Intern Med 1943;72:69-77.

23. Mutchnik MG, Lerner E, Conn HO. Effect of portocaval anastamosis on hypersplenism. Dig Dis Sci 1980;25:929-38.

24. Sullivan BH, Tumen HJ. The effect of portocaval shunt on thrombocytopenia associated with portal hypertension. Ann Intern Med 1961;55:598-603.

25. Soper NJ, Nikker LF. Effect of operations for variceal hemorrhage on hypersplenism. Am J Surg 1982;144:700-3.

26. Hutson DG, Zeppa R, Levi J, et al. The effect of distal splenorenal shunt on hypersplenism. Ann Surg 1977;185:605-12.

27. Ferrara J, Ellison C, Martin EW, et al. Correction of hypersplenism following DSRS. Surgery 1979;86:570-3.

28. Pusnani K, Sillin L, Kaplan D, et al. Effect of transjugular intrahepatic portosystemic shunt on secondary hypersplenism. Am J Surg 1997;173:169-73.

29. Bashour FN, Teran JC, Mullen KD. Prevalence of peripheral blood cytopenias (hypersplenism) in patients with nonalcoholic chronic liver disease. Am J Gastroenterol 2000;95:2936-9.

30. Liangpunsakul S, Sithat M, Ulmer B, et al. Predictors and implications of severe hypersplenism in patients with cirrhosis. Am J Med Sciences 2003;326:111-16.

31. Zein CO, Lindor KD, Angulo P. Prevalence and predictors of esophageal varices in patients with primary sclerosing cholangitis Hepatology 2004;39:204-10.

32. Pilette C, Oberti F, Aube C, et al. Non-invasive diagnosis of esophageal varices in chronic liver diseases. J Hepatol 1999;31:867-73.

33. Zaman A, Hapke R, Flora K, Rosen HR, Benner K. Factors predicting the presence of esophageal or gastric varices in patients with advanced liver disease. Am J Gastroenterol 1999;94:3292-6.

34. Madhotra R, Mulcahy HE, Willner I, Reuben A. Prediction of esophageal varices in patients with cirrhosis. J Clin Gastroenterol 2002;34:81-5.

35. Sanyal AJ, Fontana RJ, Di Bisceglie AM, et al; and the HALT-C Trial Group. The prevalence and risk factors associated with esophageal varices in subjects with hepatitis $\mathrm{C}$ and advanced fibrosis. Gastrointest Endosc 2006;64:855-64.

36. Felix WR, Myerson RM, Sigel B, et al. The effect of portocaval shunt on hypersplenism. Surg Gyn Obs 1974;139:899-904.

37. Jackson FC, Perrin EB, Smith AG, et al. A clinical investigation of the portocaval shunt-II: Survival analysis of the prophylactic operation. Am J Surg 1968;115:22-42.

38. Rousselot LM, Pantre WF, Bono RF, et al. Experiences with portocaval anastamosis: Analysis of 104 elective end to side shunts for the prevention of recurrent hemorrhage from esophagogastric varices (1952-1961). Am J Med 1963;34:297-307.

39. Morris PW, Patton TB, Balint JA, et al. Portal hypertension, congestive splenomegaly and portocaval shunt. Gastroenterol 1962;42:555-9.

40. Puttini M, Marni A, Montes F, et al. The effect of portasystemic shunt on hypersplenism: Clinical study in 129 patients with cirrhosis. Am J Surg 1979;45:444-8.

41. McAllister E, Goode S, Cordista AG, et al. Partial portal decompression alleviates thrombocytopenia of portal hypertension. Am J Surg 1995;61:129-31.

42. Mutchnick MG. Lerner E, Conn HO. Effect of portocaval anastamosis on hypersplenism. Dig Dis Sci 1980;25:929-38.

43. Macpherson AI, Innes J. Peripheral blood picture after operation for portal hypertension. Lancet 1953;264:1120-3.

44. Vang J, Simert G, Hansson JA, et al. Results of a modified distal spleno-renal shunt for portal hypertension. Ann Surg 1977;185:224-8.

45. Gschwantler M, Vavrik J, Gebauer A, et al. Course of platelet counts in cirrhotic patients after implantation of a transjugular intrahepatic portosystemic shunt - a prospective, controlled study. J Hepatol 1999:30:254-9.

46. Kishore G, Pursnani MD, Sillin LF, et al. Effect of transjugular intrahepatic portosystemic shunt on secondary hypersplenism. Am J Surg 1997;173:169-73.

47. Jalan R, Redhead DN, Allan PL, et al. Prospective evaluation of haematological alterations following the transjugular intrahepatic portosystemic stent-shunt (TIPSS). Eur J Gastroenterol Hepatol 1996;8:381-5

48. Lawrence SP, Lezotte DC, Durham JD, et al. Course of thrombocytopenia of chronic liver disease after transjugular intrahepatic portosystemic shunts (TIPS). A retrospective analysis. Dig Dis Sci 1995;40:1575-80.

49. Sanyal AJ, Freedman AM, Purdum PP, et al. The hematologic consequences of transjugular intrahepatic portosystemic shunts. Hepatology 1996;23:32-9.

50. Karasu Z, Gurakar A, Kerwin B, et al. Effect of transjugular intrahepatic portosystemic shunt on thrombocytopenia associated with cirrhosis. Dig Dis Sci 2000;45:1971-1976.

51. Jabbour N, Zajko A, Orons P, et al. Does transjugular intrahepatic portosystemic shunt (TIPS) resolve thrombocytopenia associated with cirrhosis? Dig Dis Sci 1998;43:2459-62.

52. Preneta E, Garcia-Tsao G, Grace ND, et al. Effect of propranolol therapy on platelet counts in cirrhotic patients with portal hypertension. Hepatology 1998;28,4 Pt 2:A1163 (Abstr).

53. Sekai K, Iwao T, Oho K, et al. Propranolol ameliorates thrombocytopenia in patients with cirrhosis. J Gastroenterol 2002;37:112-8.

54. McHutchinson JG, Dusheiko G, Shiffman ML, et al. Eltrombopag for thrombocytopenia in patients with cirrhosis associated with hepatitis C. N Engl J Med 2007;357:2227-36.

55. Del Rio RA, Post AB, Singer ME. Cost-effectiveness of hematologic growth factors for anemia occurring during hepatitis $\mathrm{C}$ combination therapy. Hepatology 2006;44:1598-1606.

56. Spiegel BM, Chen K, Chiou CF, et al. Erythropoietic growth factors for treatment-induced anemia in hepatitis C: A cost-effectiveness analysis. Clin Gastroenterol 2005;3:1034-42. 


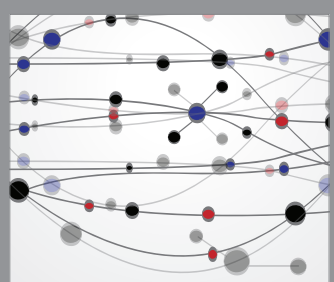

The Scientific World Journal
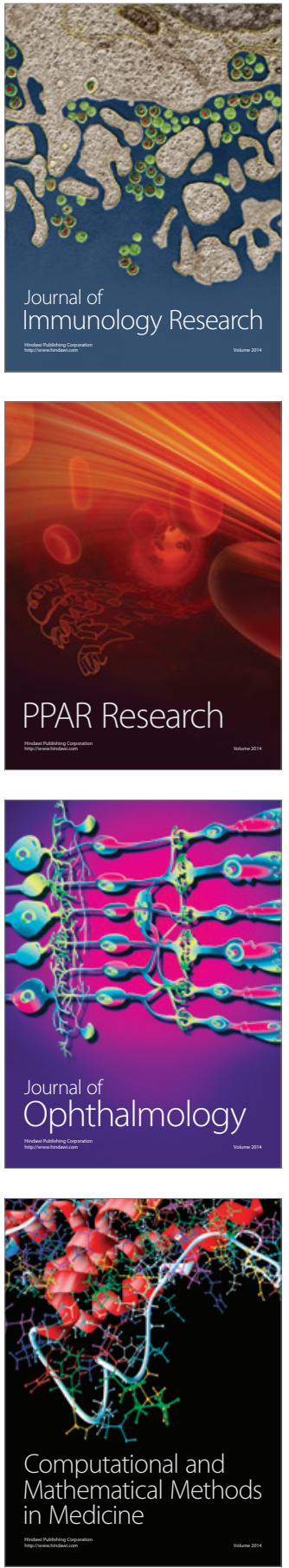

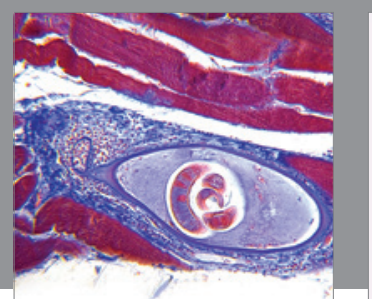

Gastroenterology Research and Practice

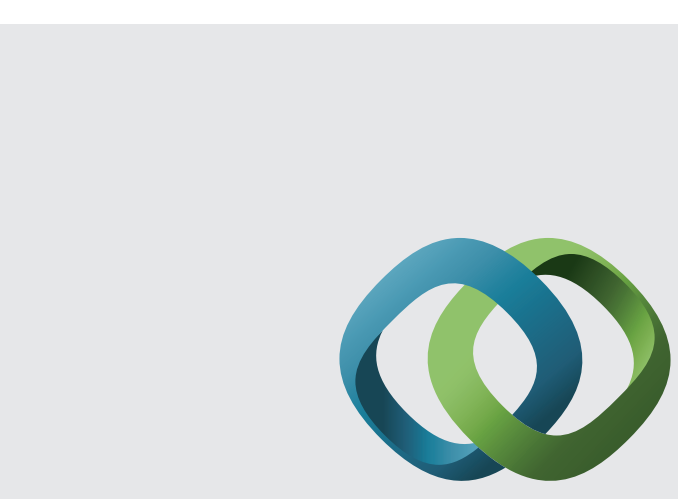

\section{Hindawi}

Submit your manuscripts at

http://www.hindawi.com
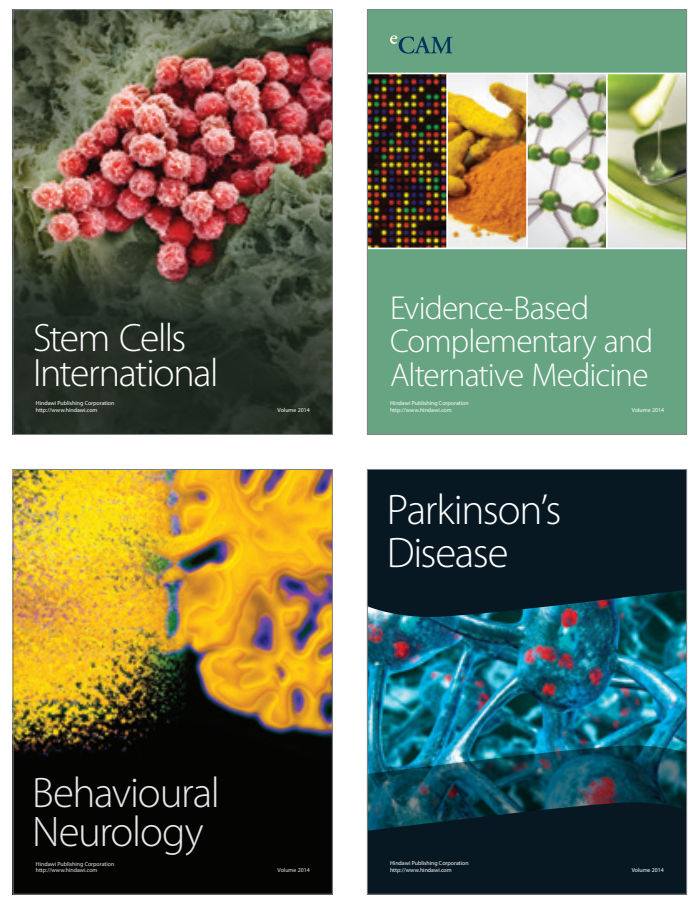
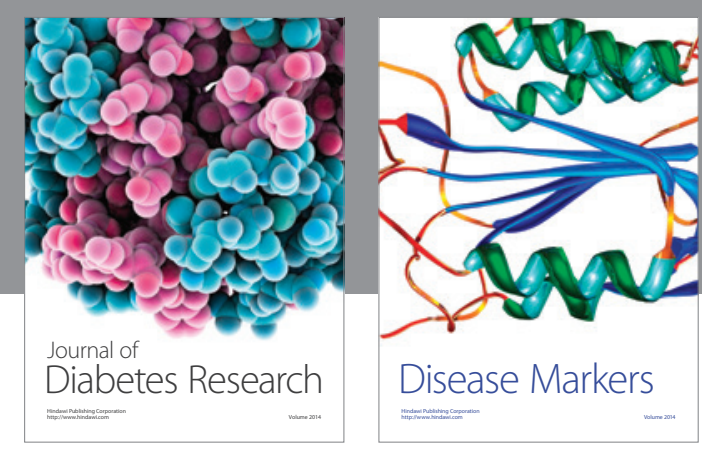

Disease Markers
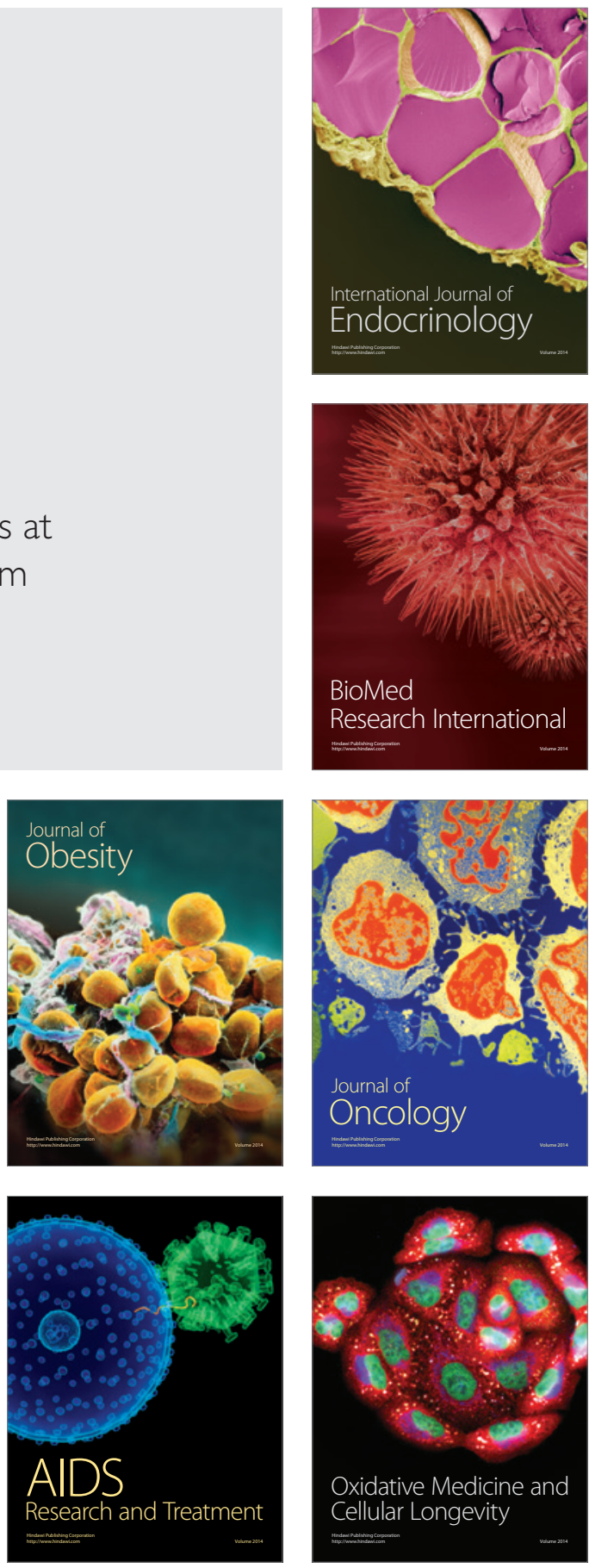